\title{
Mining as a scar on the landscape
}

\author{
H. Burge Environmental Resources Management, Australia
}

\begin{abstract} completion of mining activities. the less disturbing, the landform will be to the community and to the regulators. that appears more natural. This can be an expensive operation. geomorphic design approach includes:

- formations that are non-geometric and organic in form

- features that mimic profiles in the existing landscape

- landscapes that reflect locally present stable landforms.
\end{abstract}

Social perception is an important component in the approval and community engagement process, for a new mining project, extensions to an existing mine and the acceptance of the final landform at the

People's perception of the landscape is constructed from views to the mine from surrounding viewpoints, from roads and highways, from houses and places of work, even from aerial views and it is the amalgamation of all these views which forms a person's 'cognitive landscape', the image of the landscape that people have in their mind. When assessing acceptability of a change then the more that the final landscape appears a 'natural' component of the cognitive landscape, the more appealing or importantly,

Mining often generates quantities of waste rock material that are stored, in a benched and un-natural geometric landform. This un-natural landform is not an appealing feature within a cognitive landscape. At the end of mine life a mining company can be asked to change the form of this 'mining landscape' to one

However, waste rock dumps and tailings storage facilities can be creatively formed in a way that mimics nature and that people will find aesthetically appealing while still providing a stable land form and a basis for the reestablishment of indigenous plant communities. This is fundamentally different from a standard engineering approach that creates a landform that is purely based on engineering constraints. The

Geomorphic design principles can provide a basis for a sustainable landscape that, at closure will not be perceived as elements to be fixed in a final bout of rehabilitation, often at considerable cost.

There is also the issue of how to best communicate the changes that would be brought about to the landscape to the regulators, the community and cognitive landscapes.

This paper will give examples of geomorphic design and show how these can be communicated successfully to the broader community.

\section{$1 \quad$ Introduction}

Decision makers, communities and other stakeholders such as NGOs are seeking to have full and open disclosure of impacts which include the changes that will result to the landscape. The Performance Standards on Environmental and Social Sustainability (IFC, 2012) within the International Finance Corporation (IFC) Guidelines highlight the need for Free and Prior Informed Consent (FPIC) through full disclosure of the impacts of a proposal to an affected community.

Stakeholder engagement is a key component to determining community held values for an area and how these values relate or create a cognitive landscape. A successful consultation process increases the community's sense of ownership and partnership. 


\section{2}

\section{The problems}

Communities have a fundamental interest in the impacts of proposed mining activities and related infrastructure. They partly judge the acceptability of these changes on the alterations they perceive to their cognitive map of their landscape. A community's cognitive landscape is derived from views and experiences of natural areas and farmland, game and animal migration routes, existing infrastructure, topographical features, vegetation and locations of cultural significance in a complex overlay that exists independently of static views.

Engineering drawings and aerial views are often used to illustrate how proposed mining activities may look and from these it is expected that the community will be able to understand the impact on a community's cognitive landscape.

Engineering and aerial views similar to the example in Figure 1 clearly show an un-natural landscape, comprising regularly benched surfaces and rectangular water bodies. Based on such illustrations it is likely that the reaction will be negative. The problem is not solved by combining proposed layout plans onto an aerial. Figure 2 shows a mining plan for a mine with the proposed mining areas, servicing routes and major buildings shown as a wire-frame over the aerial.

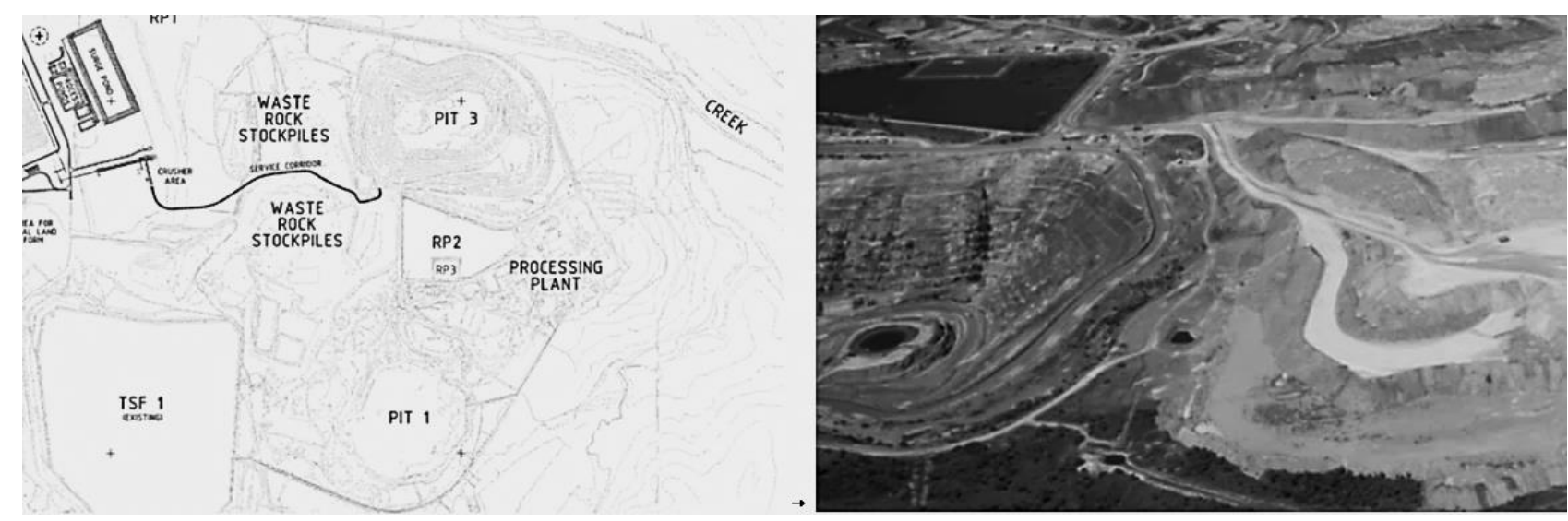

Figure 1 Example engineering drawings and aerial view

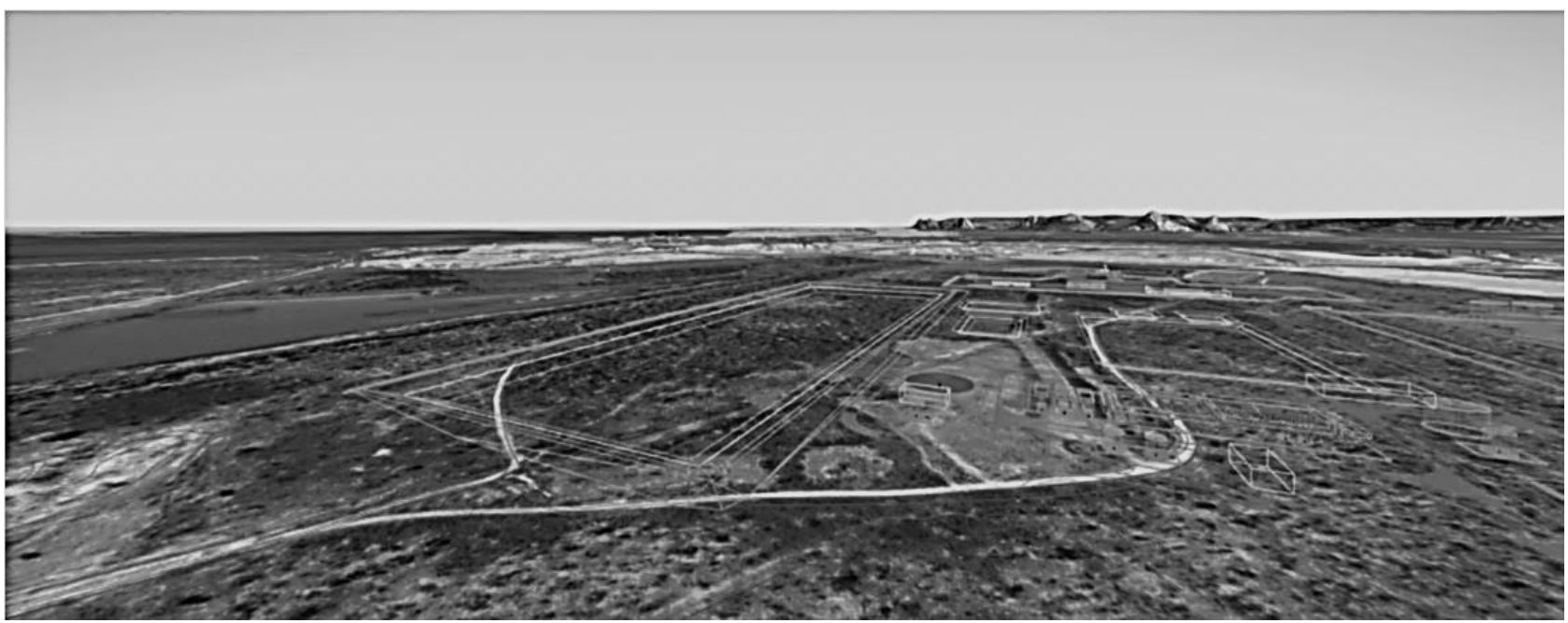

Figure 2 Typical engineering plan for proposed mining activities

Engineering drawings and aerial views with draped aerial photographs are poor at illustrating changes to the landscape and often over emphasise the visual impacts of a mine. Such illustrations may help to explain the project but can exacerbate community concerns. When engineering plans which show mine pits, terminal faces, haul roads and waste rock dumps are relied upon to interpret the proposed mining 
activities, these often confuse. Whilst these plans contain all the necessary information upon which to make a technically sound appraisal of the project, engineering plans do not offer the necessary information for a local community to determine impacts of a mining proposal on their cognitive understanding of the landscape. Therefore, the problems are twofold.

The first is the nature of the additions to the landscape, particularly those that will remain when mining activities are completed. If these additions appear un-natural then re-working may be required at completion, these may be delays with divestment or there may be significant stakeholder dis-content. If earthworks require further work for stability in the long term, once again re-working will be required at completion. These costs could far exceed the financial provisions for mine closure.

The second problem relates to how people perceive the landscape and how proposed changes can be better illustrated by not solely relying on engineering drawings or aerial views. Fly-throughs and aerial perspectives may explain the project, but confuse or, in many instances, dramatically overstate the visual implications. A clear distinction needs to be made between graphics explaining the project and graphics explaining the visual implications of the project. It is these visual implications that inform people's cognitive landscape.

\section{The first solution - geomorphic design/design with nature}

Community concerns centre on permanent changes that will change the landscape in an artificial manner. Partly this is brought about by vegetation changes, but topographical profiles are a major source of concern and their treatment is often left too late within the mine lifecycle. There are parallel engineering concerns regarding long-term stability, water quality and erosion issues of the final landform post completion.

Figure 3 shows that a design with nature or a geomorphic design approach are similar and are both firmly founded in the need for:

- the mine closure plan to be tolerant of changes over time

- for the landforms to be sustainable without excessive requirements

- for maintenance and for the vegetative strategy to be based on an acknowledgement of the evolutionary process within a plant community.

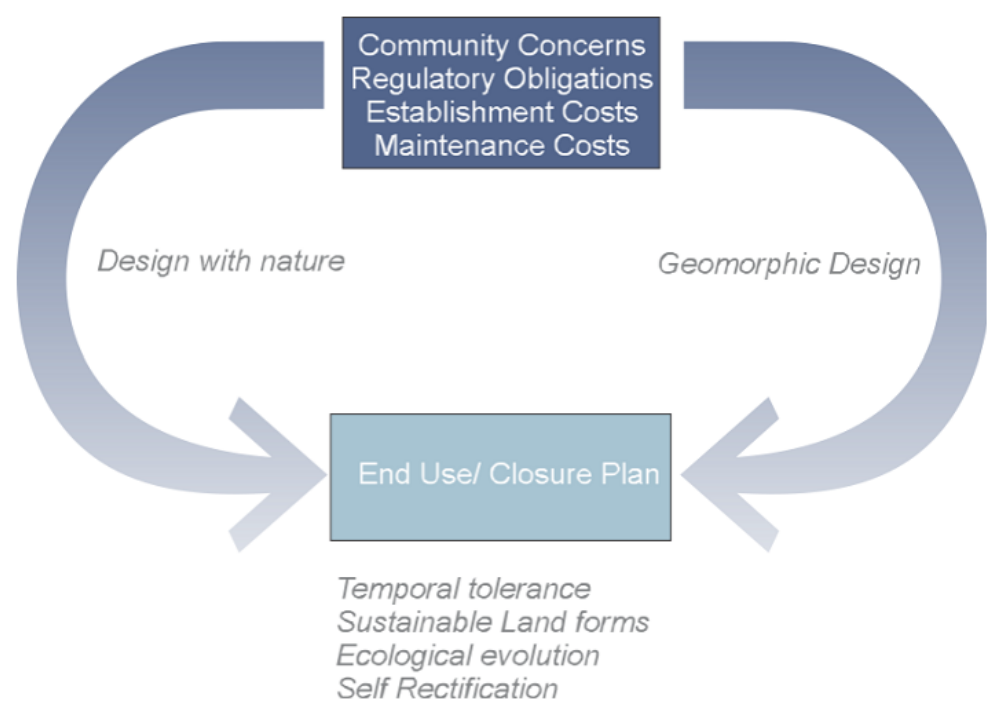

Figure 3 Mine closure strategy

Guidelines such as the 'Landform Design for Rehabilitation, Best Practice Environmental Design in Mining' (Environment Australia, 2002) have for years sought to minimise "the need to extensively reshape areas disturbed by mining and waste disposal". 
However, mine planning can go further than just ensuring the early works remain stable at completion. Design can take cues from the surrounding landscape with a design approach has been labelled as geomorphic design. Design with nature is similar in principle however design is based on natural systems such geomorphological features and characteristics of the existing vegetation found in the locality of the mine. The geomorphic design approach includes:

- formations that are non-geometric and organic in form

- features that mimic profiles in the existing landscape

- landscapes that reflect existing stable landforms.

Long-term stability and aesthetic considerations are both considered when a geomorphic approach is taken to the design of water bodies and embankment slopes. A geomorphic design of a drainage layout for a waste rock dump may be based on a dendritic drainage pattern formed in similar sized material in the locality to produce a sustainable landscape.

Water pondage areas are one example that can be created based on locally occurring features in the landscape as shown in Figure 4.
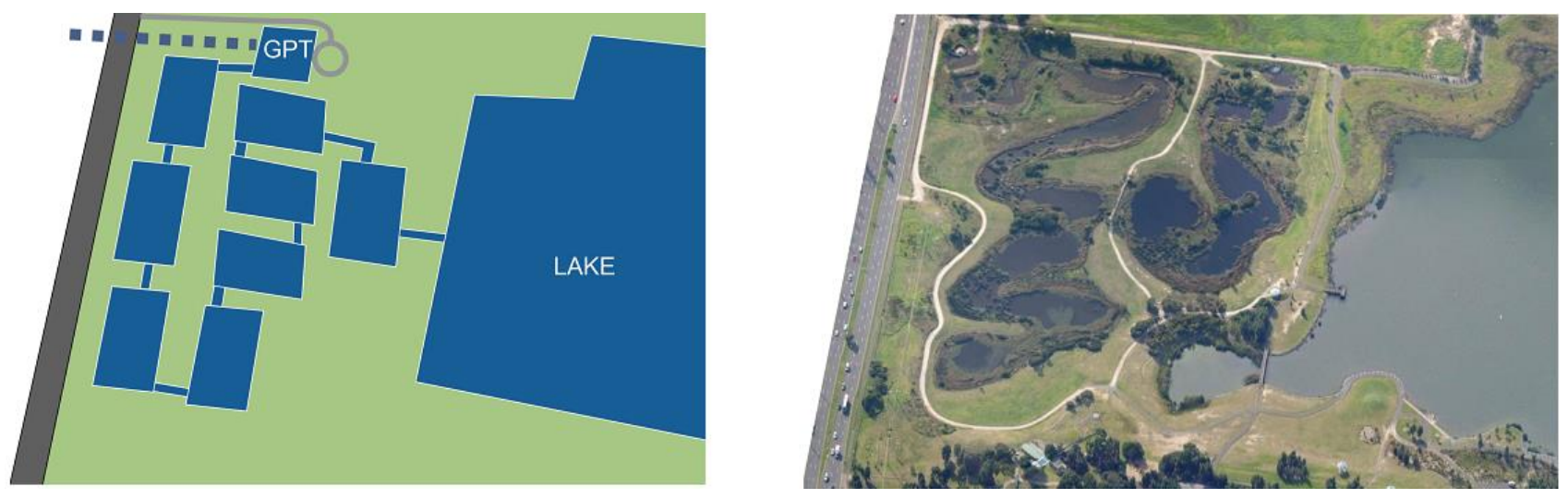

Figure 4 An engineered stormwater treatment compared with the final design

Figure 4 shows a wetlands design for a former sand mine in Victoria that evolved from the engineering modelling to a naturally appearing wetland system reflective of the oxbows and meanders of a natural water course. The completed project is an example of geomorphic design where the use of a natural system as a basis for design provided a more functional solution than the original standard engineering approach. The resulting landscape not only met the needs of engineering performance requirements, it has also been accepted by all stakeholders and has enhanced their cognitive landscape.

A similar geomorphic design approach was used in the design of a terminal face for a large quarry also in Victoria.

Figure 5 shows how the profile of Mt Pilot was used as the basis for a final quarry profile. Although there was community opposition to the quarry, when this proposal was submitted to the regulators, the quarry was approved. In the decision the mimicking of vegetative patterns and final landform profile were important criteria in the granting of the permit. Staged operations through the years of the quarry's operational life were then geared towards achieving the final form. Reworking of the staged terminal faces at completion will not be required. 

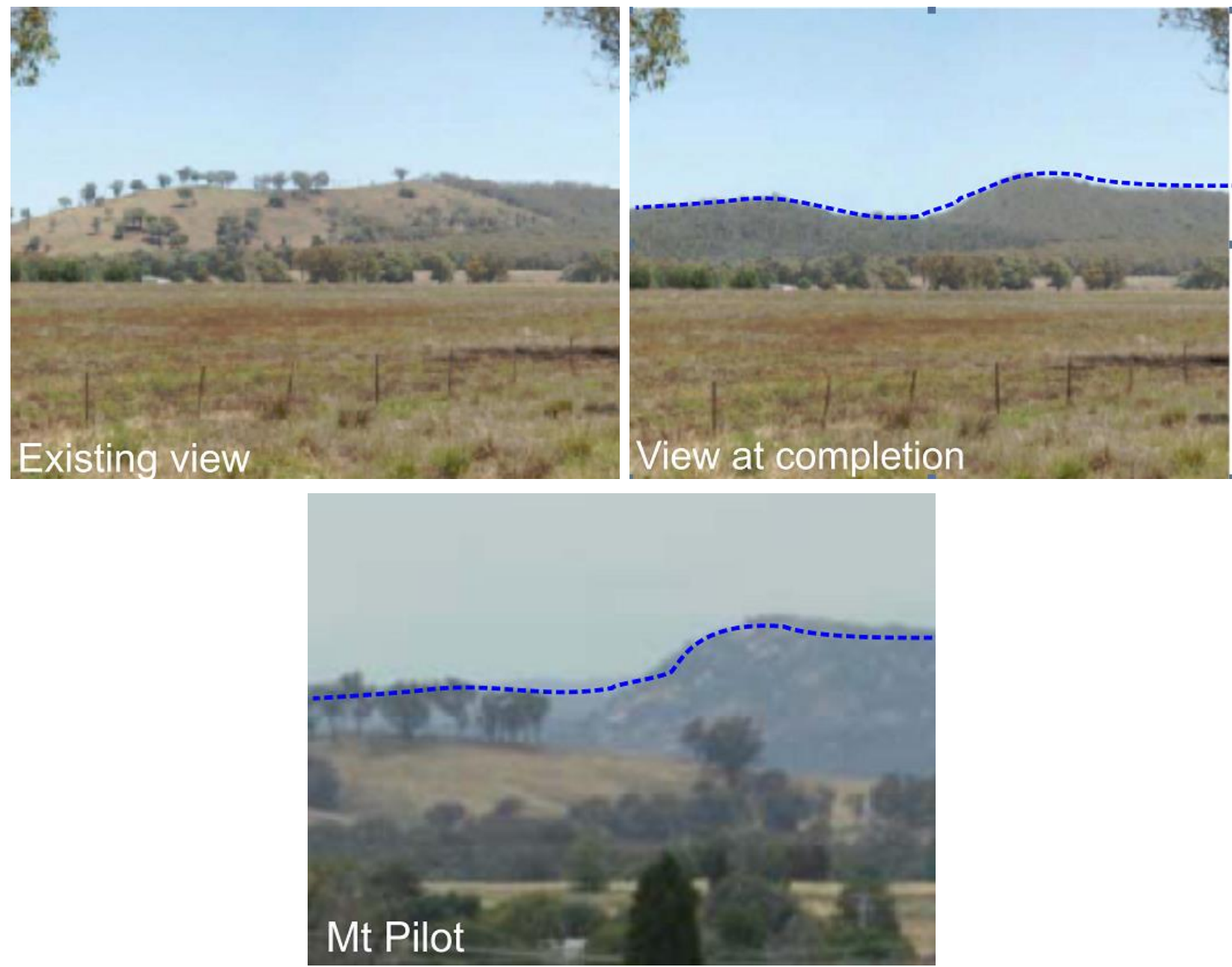

Figure 5 The final quarry face mimics that of a nearby mountain, Mt Pilot

\section{$4 \quad$ The second solution - community engagement}

Communication tools are available that allow the community to visualise a project's appearance and to understand the implications on their cognitive landscape. It is worthwhile stressing that the aim of the communication tools are to communicate the visual implications of the project, not to illustrate the project. There is a great difference between the two objectives.

Engineering drawings and flyovers, which afford birds' eye views of a proposed mine and are typically aerial photographs draped over a 3D terrain model, can accurately describe the project and are useful communication tools for project teams and regulators. However they are less useful in communicating how the mine may change the cognitive landscape of a community. Aerial perspectives often over emphasise the visual implications as people do not build up that response to the landscape from the air. Other communication tools are better suited to explore the implications of a proposed mine on a community's view including photomontages and graphics.

\subsection{Photomontages}

Photomontages prepared from selected locations to provide the ability to illustrate the potential change to the community's cognitive landscape brought about by mining activities. It is important that the viewpoint locations for photomontages are carefully selected, preferably following consultation with the local community and key stakeholders. The points that are important in defining a community's cognitive landscape can then be recognised and to which the photomontages relate. When an analysis of the 
potential impact of the proposed mining activity is undertaken from these selected viewpoints the impact of the mine on a community's cognitive landscape can be better explored.

The selection of viewpoints for photomontages can sometimes be obvious, say a bend on a road with clear views across the mine to a mountain. Figure 6 shows one such view from a local road, running past a proposed mine expansion in the Northern Territory.
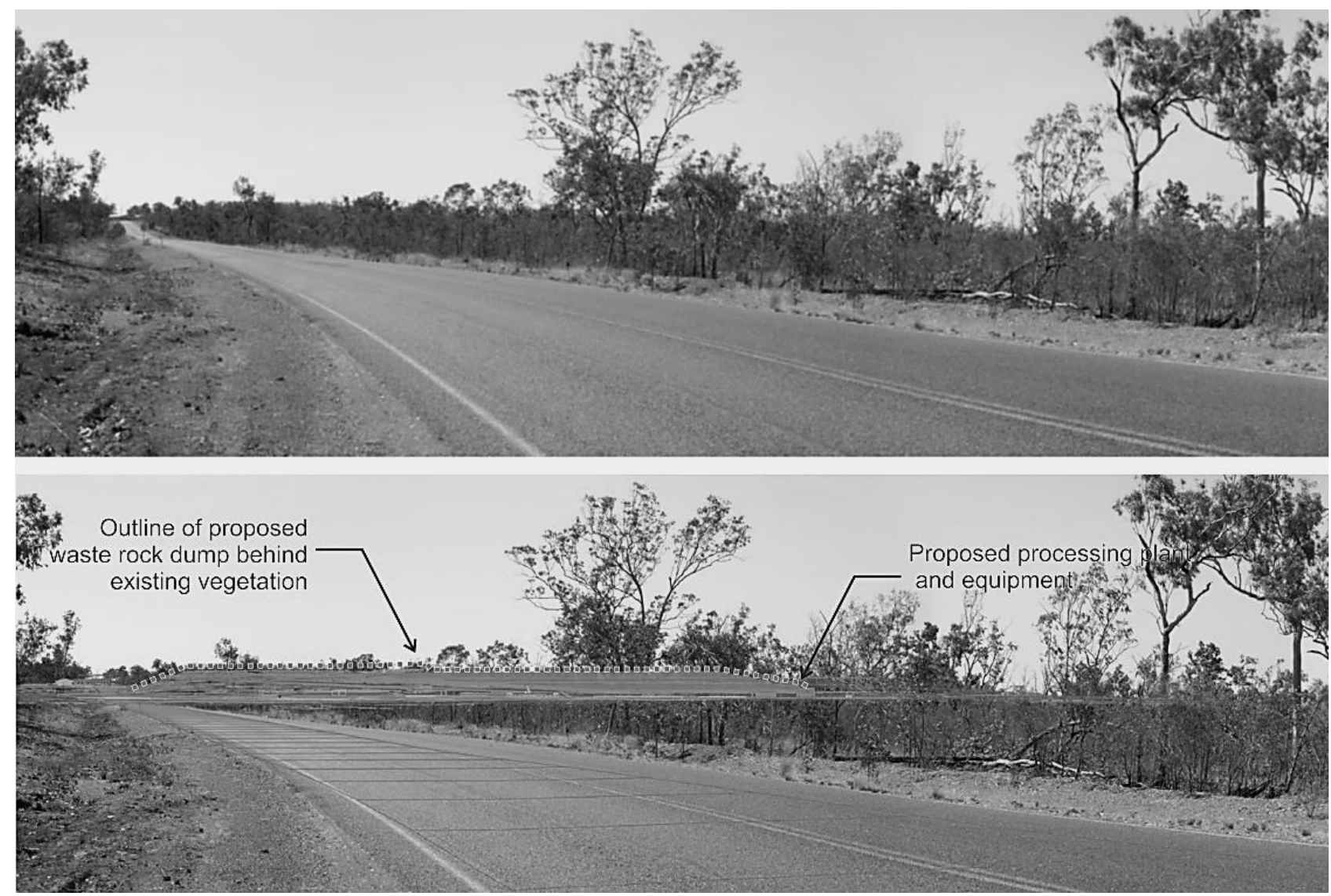

\section{Figure 6 Existing view and the mining operations - impact negligible}

There was a concern that the mining operations particularly the size and location of the proposed waste rock dump, would dominate this view. However, the photomontage shown in Figure 5 made it clear that there would be no change to the existing views from the road.

However, the selection of viewpoints is often not that obvious. In this particular project an equally important viewpoints was from another location off the road that had cultural connections. In a seemingly featureless treed and grassed area was the site of cultural significance to the community. The impacts of the mine from this location were more important to the community than the view from the road. Figure 7 shows the view from this location with an outline of the proposed waste rock dump.

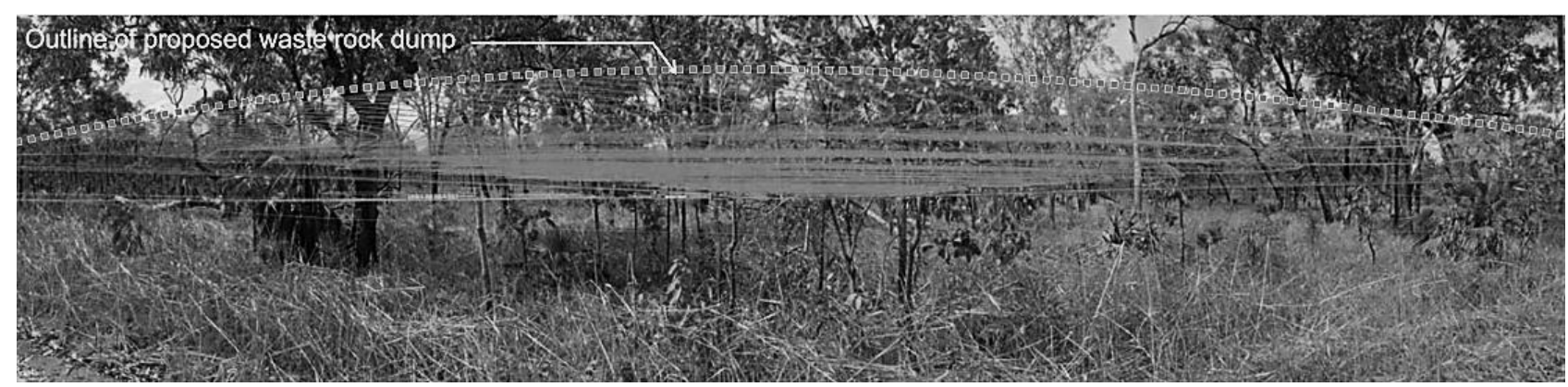

Figure 7 Existing view and the mining operations - impact high 
The photomontages from the grassed area illustrated that the proposed waste rock dumps would be intrusive to the community's cognitive landscape. As a result a decision was made to relocate the waste rock dumps.

Neither of these conclusions, that the impact from the road would be negligible, nor the impact from the cultural site would be high, were evident from the engineering drawings. In fact it appeared as if the impact would be greater from the road and insignificant from the open grassland area whereas the reverse was the case. These conclusions illustrate the difference between a description of the project and a description of the impact of the project. They emphasise the importance of utilising the correct communication tools.

A key to the success of this approach was that the photomontages were also able to be verified by the community. The community were given enlarged photomontages (printed on AO sheets) and were asked to verify the scale of the impact by going to the viewpoint location and holding the photomontage with the existing conditions photograph at arm's length. When the actual view from this location was compared with the printed sheet, the existing view appeared to be of similar (or slightly larger) size on the photomontages.

This simple test allowed the community to feel that the photomontages were accurate and they could 'trust' the images in the photomontages. It is important that photomontages are both technically correct and perceptually correct to be used for community engagement.

As well as selecting the appropriate tool, these photomontages and other visual aids needed to be believable. An 'artist's impression' often used to show an impact is typically misleading.

\subsection{Graphic communication rather that legal texts}

Mining also can offer benefits such as alternative or new access ways to an affected community and other community infrastructure. At a mining project in Papua New Guinea there was some uncertainty in the community as to what had been promised as part of an Integrated Benefits Package. When the benefits are presented as part of a complex legal document, the items of interest may be misunderstood. What we found was that through the use of simple graphics, almost cartoon in style, the community were able to more easily interpret the proposed infrastructure works contained within the Integrated Benefits Package than complex drawings or written legalistic texts.

Figure 8 shows one such graphic that was used in presentations to the affected mining community in Papua New Guinea. These graphics allowed the mining company and the community to agree on a range of benefits incorporated into an 'Integrated Benefits Package'. Issues that were addressed included access provisions, areas where the village wished to expand, locations for future church and community buildings as well as simple provisions of a footpath adjacent to the road which was used for mining traffic.
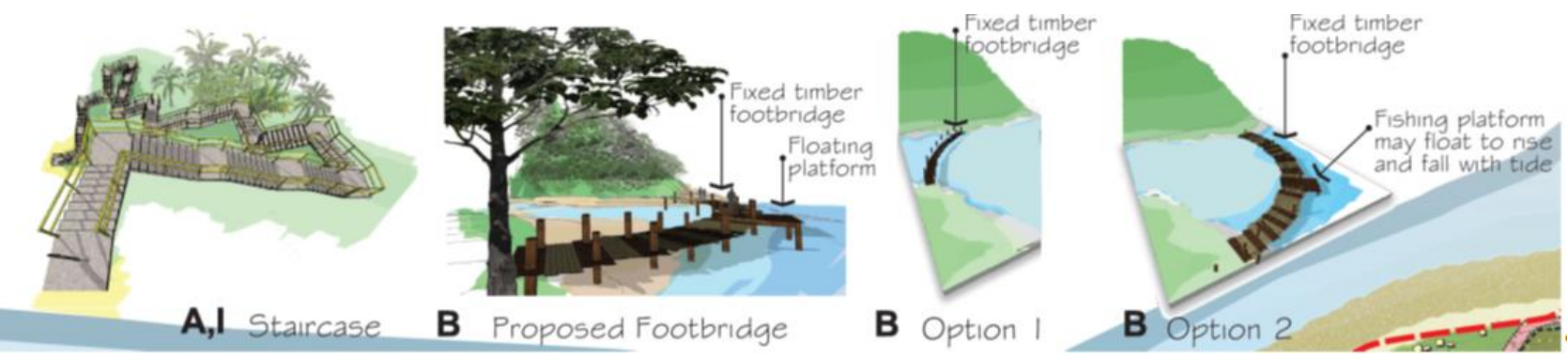

Figure 8 User-friendly graphics to show proposed community infrastructure

Much more effective engagement with the community was enabled through the visual communication tools rather than through a complex legal contractual document. 


\section{Conclusion}

Social perception is an important component in the approval and community engagement process, for a new mining project, extensions to an existing mine and the acceptance of the final landform at the completion of mining activities.

People's perception of the landscape is constructed from experiences and views to the mine from surrounding viewpoints, from roads and highways, from houses and places of work, even from aerial views and it is the amalgamation of all these views which forms a person's 'cognitive landscape', the image of the landscape that people have in their mind.

Geomorphic design offers tools to link post-mining landforms to the community's cognitive landscape, as well as creating more cost effective, sustainable landforms that lead to long term stability, lower maintenance costs and return of the land to the community.

This paper has also highlighted the need for effective visual communication tools that work hand in hand with good design so that people can understand the implications of mining operations on their cognitive landscape.

\section{References}

Environment Australia (2002) Landform design for rehabilitation, Overview of Best Practice Environmental Management in Mining, Department of the Environment, pp. 44-45.

IFC (2012) International Finance Corporation, Guidelines, Performance Standards on Environmental and Social Sustainability, January 1, 2012. 